\title{
The Role of Radiotherapy in Neoadjuvant Treatment of Patients with Operable Pancreatic Head Cancer
}

\section{Korytova*, DA Sklyar, AV Pavlovsky, EV Vlasova, AA Polikarpov, OV Korytov and VE Moiseenko}

Federal State Budgetary Institution "Russian Scientific Center of Radiology and Surgical Technologies Named After Academician A.M. Granov" of Ministry of Health of the Russian Federation, St. Petersburg, Russia

*Corresponding Author: LI Korytova, Federal State Budgetary Institution "Russian Scientific Center of Radiology and Surgical Technologies Named After Academician A.M. Granov" of Ministry of Health of the Russian Federation, St. Petersburg, Russia.
Received: September 28, 2021

Published: October 25, 2021

(C) All rights are reserved by LI Korytova., et al.

\begin{abstract}
In the article "The role of radiotherapy in neoadjuvant treatment of patients with operable pancreatic head cancer" results of the combined neoadjuvant treatment of operable pancreatic cancer were presented. Patients, suffering from pancreatic cancer $(\mathrm{n}=40$ ) were randomized into two arms and compared arm one: intra-arterial chemotherapy + radiation therapy +operation $(\mathrm{n}=20) \mathrm{vs}$ arm two: intra-arterial chemotherapy + operation $(n=20)$.

Neoadjuvant radiation therapy was performed with 2 fractions per day 2 Gy each with 4-6 hours between them 5 days a week up until summary dose of 50 Gy. Neoadjuvant radiation therapy with a double fractioning per day had proven to be safe and effective. Arm 1 had statistically verified lower postoperative pancreatitis frequency and chances to develop fistulas, higher number of second degree pathomorphosis outcomes, as well as life expectancy median.
\end{abstract}

Keywords: Radiation Therapy; Pancreatic Cancer; Double Day Fractioning

\section{Introduction}

Pancreatic cancer (PC) ranks $7^{\text {th }}$ in the worldwide cancer mortality structure [1]. 15312 new cases of the disease were detected in Russia in 2019. The proportion of patients with stage I-II pancreatic cancer was $20.6 \%$ in the same year [2]. The recommended standard of treatment for operable pancreatic cancer is surgical treatment with the use of neo- and adjuvant chemotherapy $[3,4,5]$. Modern neoadjuvant chemotherapy (CT) improves the long-term results of combined treatment of patients with PC and increases the overall survival median [6].
However, there have been publications on high efficiency of radiation factor inclusion into the neoadjuvant treatment algorithm in the past few years [7].

According to the meta-analysis carried out by Cloyd J. M., et al. (2020), neoadjuvant therapy showed a clear trend towards improved treatment outcomes, increasing the overall survival median to 25 months in comparison with the group of patients who underwent surgery alone [8]. The pancreatic cancer tissue is radiation resistant, therefore, to overcome the resistance effect, a combination of radiation and chemotherapeutic radiomodifying 
factors was used. The use of radiation therapy (RT) in combination with chemotherapy (CT) as a neoadjuvant in the PREOPANC-1 study showed an increase in the $\mathrm{R} 0$ resection rate, an increase in the progression-free period, and a decrease in the rate of local recurrence. In combination with adjuvant treatment in the chemoradiotherapy group, overall survival median reached 35.2 months [9]. The applied regimens of neoadjuvant chemotherapy, such as FOLFIRINOX and gemcitabine and nab-paclitaxel are quite effective, however, they are toxic and are not always well-tolerated by patients, especially in combination with RT [10]. The emergence of adverse events during neoadjuvant chemotherapy makes it necessary to postpone the planned stage of surgical intervention. This, in combination with incomplete preoperative anticancer treatment, can worsen the results of treatment. To reduce the incidence of adverse events resulting from chemotherapy, several studies have used transcatheter arterial infusion of chemotherapy drugs as neoadjuvant modes. Changes in the method of administration of chemotherapy contributed to a decrease in overall toxicity, an increase in the median of the period before relapse (time to progression), and overall survival compared with surgery alone [11,12]. There are various approaches to reduce the toxicity of radiation therapy, one of which is the daytime crushing of the fractional dose of radiation $[24,25]$.

\section{Purpose of the Study}

The purpose of this study is to assess the safety and efficiency of patients with operable pancreatic cancer after combined use of radiation with daily double dose fractionation with intra-arterial chemotherapy.

\section{Materials and Methods}

The study includes materials from medical histories of 40 patients diagnosed with pancreatic cancer T1-3N0M0, who received treatment in the FSBI "Russian Scientific Center of Radiology and Surgical Technologies named after Academician A.M. Granov" in 2018 - 2021.

The staging of the tumor process was carried out based on the TNM classification of pancreatic cancer (8th edition, 2017) [16].

The method of blind randomization was used to compose 2 groups of 20 patients, differing in the algorithm of neoadjuvant treatment. Patients in both groups did not differ in age, stage, tumor histology, and concomitant pathology.
Neoadjuvant treatment in both groups was initiated with intraarterial chemotherapy.

Intra-arterial chemotherapy in both groups was carried out according to the method accepted in the afore mentioned clinic. Chemoembolization of the pancreatic head tumor was performed by selective injection of oxaliplatin at $85 \mathrm{mg} / \mathrm{m}^{2}$ with $4 \mathrm{ml}$ of lipiodol into the gastro-duodenal artery after preliminary catheterization of the femoral artery, according to the Seldinger technique. Intraarterial infusion of $1000 \mathrm{mg} / \mathrm{m}^{2}$ with gemcitabine was being carried out into the celiac trunk for 3 hours. At the end of the procedure, the catheter was removed.

3 - 5 days after the end of chemotherapy, the control group underwent surgical treatment in pancreatoduodenal resection.

In the study group of the study, 3 - 5 days later, radiation therapy was started on the Axesse Linear accelerator with an energy of 6 $\mathrm{MeV}$ with a double irradiation of 2.0 Gy with a 4 - 6-hour break, 5 days a week, to a total dose of 50 Gy. Duration of therapy is 12 - 14 days. 3 - 5 days after the end of the RT, surgical treatment is performed in the volume of pancreatoduodenal resection.

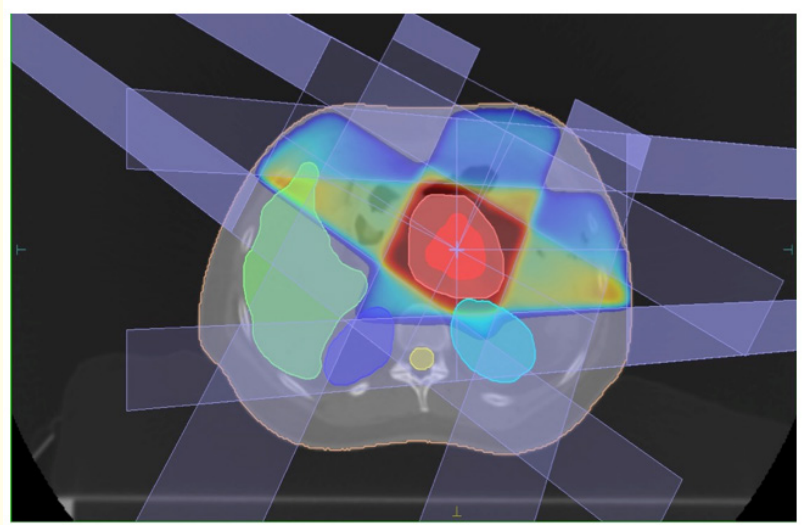

Picture 1: Radiotherapy plan.

Evaluation of adverse events of preoperative anticancer treatment in the study groups was carried out based on the CTCAE version 5.0 criteria.

To assess the therapeutic pathomorphosis in the operational material, the classification of E.F. Lushnikov has been adapted. It 


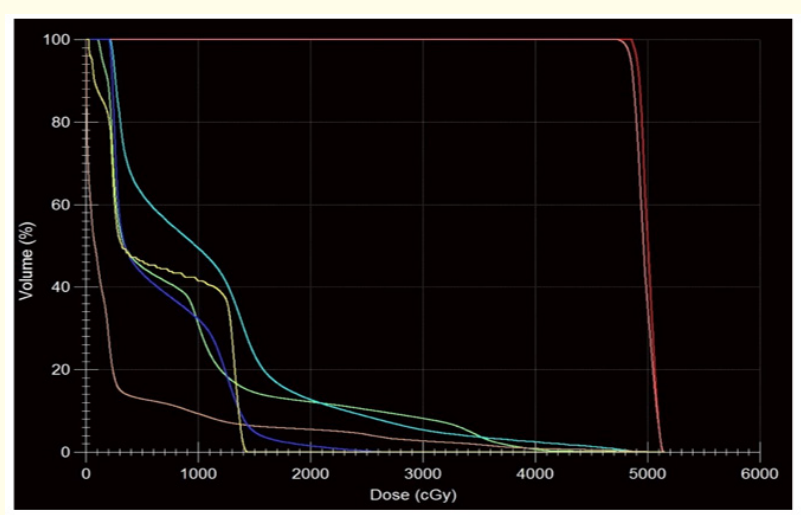

Picture 2: Dose-volume distribution. The histogram shows that the prescriptions were fully implemented.

includes 4 degrees and is characterized by the following features [13]:

- I (weak) - Dystrophic changes in individual tumor cells;

- II (moderate) - The appearance of foci of necrosis and dystrophic changes in tumor cells;

- III (pronounced) - Extensive fields of necrosis, pronounced dystrophic changes in tumor cells, few tumor cells retain their viability;

- IV (pronounced, complete) - The absence of tumor elements [13].

The study groups compared the median time to relapse (time to progression), and life expectancy.

Statistical processing of the material was carried out using Statistica for Windows version 17. The reliability of the results in the groups was determined by comparative analysis (Pearson's test), Fisher's exact method; the reliability of the mean values was determined using the Mann-Whitney U-test and the Student's test [14]. Life expectancy, survival median, time to progression and median time to progression were calculated using the Kaplan-Meier method [15].

\section{Results}

The study was dominated by patients with stage 2 of the tumor process in both the main and control groups, 18 people in each group, which is $90 \%$ of the total number (Table 1 ).

\begin{tabular}{|c|c|c|c|c|c|c|}
\hline \multirow{2}{*}{ Stage } & \multirow{2}{*}{ TNM } & \multicolumn{2}{|c|}{$\begin{array}{l}\text { Study group } \\
\quad(n=20)\end{array}$} & \multicolumn{2}{|c|}{$\begin{array}{c}\text { Control group } \\
(\mathrm{n}=20)\end{array}$} & \multirow{2}{*}{$\mathrm{p}$} \\
\hline & & $\begin{array}{l}\text { Absolute } \\
\text { number }\end{array}$ & $\%$ & $\begin{array}{l}\text { Absolute } \\
\text { number }\end{array}$ & $\%$ & \\
\hline $\mathrm{Ib}$ & T2N0M0 & 2 & 10 & 2 & 10 & 1 \\
\hline IIa & T3N0M0 & 9 & 45 & 10 & 50 & 0.752 \\
\hline IIb & T1-3N1M0 & 9 & 45 & 8 & 40 & 0.75 \\
\hline Total & & 20 & 100 & 20 & 100 & \\
\hline
\end{tabular}

Table 1: Distribution of patients by stage in the study and control groups.

Adverse events of preoperative therapy are presented in the table below. In the study group, 1 - 2 grade anemia was observed in two patients $(10 \%)$, in the control group in three (15\%). In the study group 1 - 2 grade neutropenia was observed in three (15\%) cases, and in two (10\%) cases in the control group. 1 - 2 grade thrombocytopenia was observed in two patients $(10 \%)$ in the study group. There were no significant differences in the manifestation of hematological toxicity in the groups. Among the manifestations of non-hematological toxicity, 6 patients (30\%) of the study group had 1 - 2 grade diarrhea $(\mathrm{p}=0.038)$, while it was registered with only one patient (5\%) in the control group. In the study group, nausea 1 - 2 degree observed in 5 patients (25\%), in the control group - in 3 patients (15\%). 1 - 2-degree vomiting was registered with two $(10 \%)$ patients from the study group and three patients (15\%) from the control group (Table 2).

\section{Immediate results of surgical treatment}

All patients $(n=40)$ included in the study underwent routine surgical treatment 3 - 5 days after the end of neoadjuvant therapy. Comparison of indicators of patients' condition was carried out. Significant differences in the study and control groups were found in the frequency of complications. The frequency of pancreatic fistulas of type $\mathrm{B}$ and $\mathrm{C}$ in the study group of diagnosis in 1 (5\%) patient versus $6(30 \%)$ patients $(\mathrm{p}<0.038)$; postoperative pancreatitis diagnosis in 3 patients (5\%) versus $11(55 \%)(\mathrm{p}<0.09)$, the level of pancreatic amylase after surgery was $7.4 \pm 6.09 \mathrm{U} / \mathrm{ml}$ versus $139.4 \pm 95,8 \mathrm{U} / \mathrm{ml}$ in the study group $(\mathrm{p}=0.033)$.

The average life expectancy was $24.1 \pm 1.1$ months in the study group, and $19.5 \pm 2.1$ months in the control group. The survival 


\begin{tabular}{|c|c|c|c|}
\hline $\begin{array}{l}\text { Type and Degree of } \\
\text { Adverse } \\
\text { Effects }\end{array}$ & $\begin{array}{l}\text { Study Group } \\
\qquad(\mathrm{N}=20)\end{array}$ & $\begin{array}{c}\text { Control Group } \\
(\mathrm{N}=20)\end{array}$ & $\mathbf{P}$ \\
\hline \multicolumn{4}{|l|}{ I Haematological } \\
\hline Anemia (1-2) & $2(10)$ & $3(15)$ & 0,633 \\
\hline Neutropenia (1-2) & $3(15)$ & $2(10)$ & 0,633 \\
\hline $\begin{array}{l}\text { Thrombocytopenia } \\
(1-2)\end{array}$ & $2(10)$ & $0(0)$ & 0,147 \\
\hline \multicolumn{4}{|l|}{ II Non-haematological } \\
\hline $\begin{array}{l}\text { Amylase level increase } \\
(1-2)\end{array}$ & $2(10)$ & $3(15)$ & 0,633 \\
\hline $\begin{array}{l}\text { AST } \backslash \text { ALT level in- } \\
\text { crease (1-2) }\end{array}$ & $5(25)$ & $3(15)$ & 0,430 \\
\hline $\begin{array}{l}\text { Raise in GGTP level } \\
(1-2)\end{array}$ & $3(15)$ & $2(10)$ & 0,633 \\
\hline Nausea (1-2) & $5(25)$ & $3(15)$ & 0,430 \\
\hline Vomiting (1-2) & $2(10)$ & $3(15)$ & 0,633 \\
\hline Diarrhea (1-2) & $6(30)$ & $1(5)$ & 0,038 \\
\hline
\end{tabular}

Table 2: Adverse events after preoperative therapy in the study groups.

median in the study group was $26 \pm 1.6$ months, and in the control group, $22 \pm 1.2$ months ( $\mathrm{p}=0.044$ ) (Picture 3).

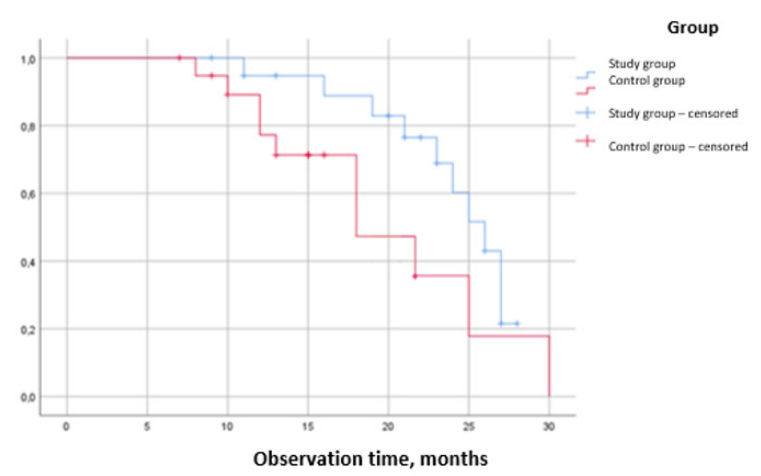

Picture 3: Life expectancy.

Based on the results of the assessment of the pathomorphological study of the removed tissues, the diagnosis of pancreatic cancer was confirmed in all patients. In the study group, 19 (95\%) patients had a therapeutic pathomorphosis, while in 6 patients (30\%) it corresponded to the $2^{\text {nd }}$ degree, in 13 cases (65\%) it corresponded to the 1 st degree. Signs of medical pathomorphosis of the $1^{\text {st }}$ degree were registered in the control group in 5 people (25\%). In the study group, there was a significant increase in the frequency of grade II therapeutic pathomorphosis ( $p=0.008)$.

During further observation of the study group, disease progression was registered in 10 (50\%) patients. One patient (5\%) had local recurrence, 7 (35\%) had liver metastases, one (5\%) had lung metastases, and one (5\%) had peritoneal carcinomatosis. In the control group, progression was observed in 11 patients: in 4 patients (20\%) local recurrence, in 6 (30\%) liver metastases and in one $(5 \%)$ peritoneal carcinomatosis (Table 3$)$.

\begin{tabular}{|l|c|c|c|}
\hline Indicator & $\begin{array}{c}\text { Study } \\
\text { Group }\end{array}$ & $\begin{array}{c}\text { Control } \\
\text { Group }\end{array}$ & P \\
\hline Local recurrence & 1 & 4 & 0,152 \\
\hline Liver metastases & 7 & 6 & 0,736 \\
\hline Lung metastases & 1 & - & 0.312 \\
\hline $\begin{array}{l}\text { Peritoneal } \\
\text { carcinomatoses }\end{array}$ & 1 & 1 & 1 \\
\hline
\end{tabular}

Table 3: Relapse profile in study groups.

The average time to progression was $22.8 \pm 1.6$ months in the control group, and $17.9 \pm 1.9(\mathrm{p}=0.043)$ months in the control group. The median time to progression in the study group was $23 \pm$ 4.1 months, and in the control group - $20 \pm 1.9$ months $(p=0.049)$ (Picture 4).

\section{Discussion}

The generally accepted treatment standard for operable pancreatic cancer involves surgery followed by adjuvant chemotherapy.

However, the radicalism of such treatment depends on the presence of microscopic metastases in the lymph nodes and surrounding tissues [17]. Adjuvant chemotherapy is recommended after surgical treatment for patients to reduce the frequency of early relapses and improve long-term results. However, not all patients manage to undergo CT in time due to the complicated postoperative period. 


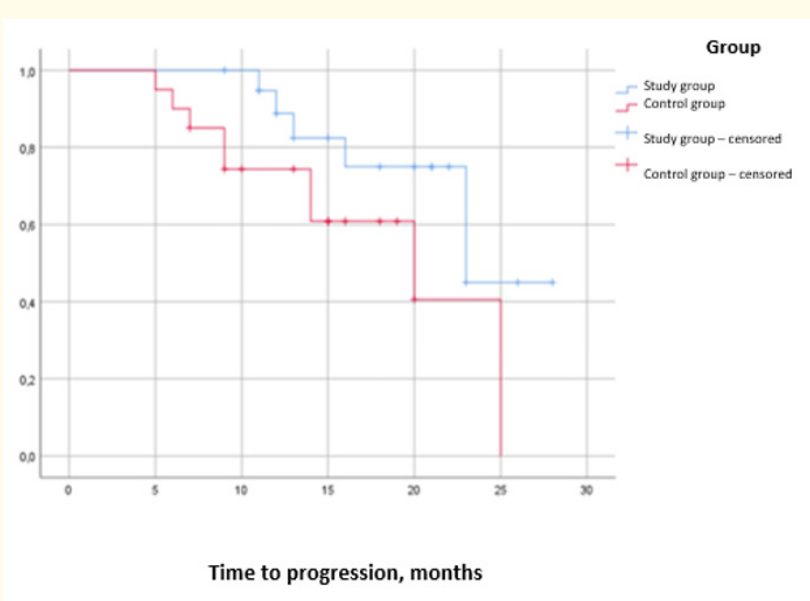

Picture 4: Time period before progression.

Theoretically, the goal of preoperative chemoradiation therapy for pancreatic cancer is to reduce the area of contact between the tumor and the vessels, increase the likelihood of a negative resection margin, and prolong survival by affecting micrometastases [19]. The use of intra-arterial chemotherapy allows the delivery of chemotherapy drugs selectively to the tumor vessels. Increasing the concentration of chemotherapy drugs in the tumor and regional lymph nodes with superfluid lipiodol allows achieving a pronounced symptomatic effect and potentiating the effect of radiation therapy $[20,21]$.

The use of intra-arterial therapy can reduce the incidence of adverse events. In our study, the frequency of adverse events was comparable to previous studies [11]. There was a significant difference in the increase in the incidence of grade 1 - 2 diarrhea in patients of the study group ( $\mathrm{p}=0.038$ ). The use of double fractionation of the radiation dose makes it possible to reduce the number of adverse events in the early postoperative period, which does not affect the surgical treatment initiation timing. In the work of Peng JS., et al. (2019), out of 71 patients who underwent preoperative chemoradiation therapy based on gemcitabine, $38.1 \%$ had a moderate response to treatment, which is comparable to our data on $30 \%$ of patients in the study group with grade II therapeutic pathomorphosis. ( $p=0.008)$ [22].
According to the data of an early study on the incidence of relapses after the use of intra-arterial chemotherapy, the frequency of local relapses was comparable and was at the level of $20 \%$ of all patients [23].

The use of conventional radiation therapy in operable pancreatic cancer patients can improve the results [19].

However, the increase of frequency of toxic effects that negatively affect the patients' condition with resectable pancreatic cancer drew attention to possible options of changing the radiation regime. Thus, we focused on publications concerning the effectiveness of the results of using a daily fractionated dose of radiation in combination with chemotherapy in the treatment of other tumor localizations.

Radiation therapy with double daily dose splitting with CT is the "gold standard of radiation" for limited stages of small cell lung cancer [25].

Double day fractionation by Coen Y., et al. 2021 was successfully used to preserve the bladder to reduce toxicity when combined with radiation with a highly toxic chemotherapy regimen of CT 5 FU + cisplatin [24].

In our study, a significant difference in pathomorphosis of the $2^{\text {nd }}$ degree was obtained in the study group compared to the control group. There was also an improvement in the survival median of the median time to progression. However, this significantly increased the frequency of diarrhea during RT.

\section{Conclusion}

1. Neoadjuvant use of a combination of radiation therapy in the multifractionation mode and intra-arterial selective administration of the drugs gemcitabine and oxaliplatin is safe and is not accompanied by a significant deterioration in the quality of patients' life. Adverse events after the use of radiation therapy did not exceed grade-2, but the differences were not significant $(p>0.05)$.

2. Radiation therapy provides in the postoperative period a significant reduction in the number of significant pancreatic fistulas (type B and C) and manifestations of pancreatitis ( $\mathrm{p}$ $=0.008)$. 
3. In the study group, an increase in the frequency of second-degree therapeutic pathomorphosis was proved $(\mathrm{p}=0.043)$.

4. The combination of radiation therapy and intra-arterial chemotherapy increases life expectancy and median survival $(\mathrm{p}=$ 0.049).

\section{Bibliography}

1. Rawla P., et al. "Epidemiology of pancreatic cancer: global trends, etiology and risk factors". World Journal of Oncology 10.1 (2019): 10.

2. Edited by AD Kaprin., et al. State of cancer care to the population of Russia in 2017. M: MNIOI P.A. Herzen branch of the Federal State Budgetary Institution "National Medical Research Center of Radiology" of the Ministry of Health of Russia (2018): 236.

3. IA Pokataev., et al. "Practical recommendations for drug treatment of pancreatic cancer". Malignant Tumors: RUSSCO Practice Guidelines 27 (2020): 492-506.

4. Ducreux M., et al. "Cancer of the Pancreas: ESMO clinical practise guidelines". Supplements - Annals of Oncology 5 (2015): 56-68.

5. Tempero MA., et al. "Pancreatic Adenocarcinoma, Version 2.2021, NCCN Clinical Practice Guidelines in Oncology". Journal of the National Comprehensive Cancer Network 19.4 (2021): 439-457.

6. Pan L., et al. "Survival benefits of neoadjuvant chemo (radio) therapy versus surgery first in patients with resectable or borderline resectable pancreatic cancer: a systematic review and meta-analysis". World Journal of Surgical Oncology 18.1 (2020): 1-13.

7. Han D., et al. "Analysis of radiotherapy impact on survival in resected stage I/II pancreatic cancer patients: a populationbased study". BMC Cancer 21.1 (2021): 1-11.

8. Cloyd JM., et al. "Neoadjuvant therapy for resectable and borderline resectable pancreatic cancer: A meta-analysis of randomized controlled trials". Journal of Clinical Medicine 9.4 (2020): 1129.
9. Versteijne E., et al. "Preoperative chemoradiotherapy versus immediate surgery for resectable and borderline resectable pancreatic cancer: results of the Dutch randomized phase III PREOPANC trial". Journal of Clinical Oncology 38.16 (2020): 1763-1773.

10. Pusceddu S., et al. "Comparative effectiveness of gemcitabine plus nab-paclitaxel and FOLFIRINOX in the first-line setting of metastatic pancreatic cancer: a systematic review and metaanalysis". Cancers 11.4 (2019): 484.

11. DA Granov., et al. "Assessment of the safety of intra-arterial chemotherapy with gemcitabine and oxaliplatin in the combined treatment of adenocarcinoma of the pancreatic head". Annals of Surgical Hepatology 22.2 (2017): 54-59.

12. Qiu B., et al. "Transcatheter arterial infusion for pancreatic cancer: a 10-year National Cancer Center experience in 115 patients and literature review". Abdominal Radiology 44.8 (2019): 2801-2808.

13. EF Lushnikov. "Therapeutic pathomorphosis of tumors". Pathological diagnosis of human tumors book. Ed.byA.V. Kraevsky, D.S. Smolyannikova, M. Sarkisova: Medicine (1993.): 560.

14. AN Gerasimov. "Medical statistics". M .: Medical Information Agency (2007): 475.

15. Kaplan EL and P Meier. "Nonparametric estimation from incomplete observations". Journal of the American Statistical Association 53 (1958): 457-481.

16. Brierley James D., et al. "TNM classification of malignant tumours". John Wiley and Sons (2017).

17. Tsai S., et al. "Evolution of the management of resectable pancreatic cancer". Journal of Oncology Practice 12.9 (2016): 772778.

18. Seshacharyulu P., et al. "Biological determinants of radioresistance and their remediation in pancreatic cancer". Biochimica et Biophysica Acta (BBA) 1868.1 (2017): 69-92.

19. Han D., et al. "Analysis of radiotherapy impact on survival in resected stage I/II pancreatic cancer patients: a populationbased study". BMC cancer 21.1 (2021): 1-11.

Citation: LI Korytova., et al. "The Role of Radiotherapy in Neoadjuvant Treatment of Patients with Operable Pancreatic Head Cancer". Acta Scientific Gastrointestinal Disorders 4.11 (2021): 36-42. 
20. AV Kozlov., et al. "Arterial chemoembolization in patients with locally advanced pancreatic cancer". Herald of Surgery 177.1 (2018): 31-36.

21. LI Korytova., et al. "Possibilities of conformal radiation therapy in the treatment of patients with locally advanced pancreatic cancer". Russian Biotherapeutic Journal 16.1 (2017): 44-45.

22. Peng JS., et al. "Pathologic tumor response to neoadjuvant therapy in borderline resectable pancreatic cancer". Hepatobiliary and Pancreatic Diseases International 18.4 (2019): 373-378.

23. AV Pavlovsky., et al. "Influence of perioperative intra-arterial selective chemotherapy on the period of recurrence of ductal adenocarcinoma of the pancreatic head after pancreatoduodenal resection". Annals of Surgical Hepatology 23.3 (2018):1422.

24. Michael Yan., et al. "A Comparison of Hypofractionated and Twice-Daily Thoracic Irradiation in Limited-Stage Small-Cell Lung Cancer: An Overlap-Weighted Analysis". Cancers 13 (2021): 2895.

25. John J Coen., et al. "Bladder Preservation With Twice-a-Day Radiation Plus Fluorouracil/Cisplatin or Once Daily Radiation Plus Gemcitabine for Muscle-Invasive Bladder Cancer: NRG/ RTOG 0712-A Randomized Phase II Trial". Journal of Clinical Oncology 37.1 (2019): 44-52.

Volume 4 Issue 11 November 2021

(C) All rights are reserved by LI Korytova., et al. 